\title{
Is Primary Hyperparathyroidism a Risk Factor for Papillary Thyroid Cancer? An Exemplar Study and Literature Review
}

\author{
Udi Cinamon $^{1}$ Dalia Levy ${ }^{1}$ Tal Marom ${ }^{1}$ \\ ${ }^{1}$ Department of Otolaryngology, Head and Neck Surgery, Edith \\ Wolfson Medical Center, Holon, Israel \\ Int Arch Otorhinolaryngol 2015;19:42-45.
}

\begin{abstract}
Address for correspondence Udi Cinamon, MD, Department of Otolaryngology-Head and Neck Surgery, Edith Wolfson Medical Center, P.O. Box 5, Holon 58100, Israel (e-mail: udicin@yahoo.com).
\end{abstract}

\begin{abstract}
Introduction Primary hyperparathyroidism (PHPT) is associated with several cancer types, including papillary thyroid carcinoma (PTC).

Objective To explore further the relation between PHPT and PTC.

Methods By considering patients with PHPT as extra-suspicious for PTC, we studied an exemplar group of patients with PHPT with a small $(\leq 1 \mathrm{~cm})$ thyroid nodule, which was negative in preoperative cytologic examination. During parathyroidectomy, a frozen section biopsy of the thyroid nodule confirmed PTC, as did the final surgical specimen, revealing that the preoperative cytology was false-negative. Additionally, relevant reports retrieved from the English literature addressing thyroid cancer and hyperparathyroidism were reviewed and processed.

Results Four patients with PHPT were studied. Three had a multifocal thyroid disease, and three had neck lymph node metastasis. Processing previous report data supported an association between PHPT and PTC. Although thyroid nodularity among patients with PHPT was similar to the general population, PTC incidence was higher. This was true also for patients with secondary hyperparathyroidism.

Conclusions This study emphasized that PHPT should be considered as a noteworthy risk factor for PTC. Fine needle aspiration of a thyroid nodule is the most valuable

Keywords

- hyperparathyroidism

- parathyroid adenoma

- thyroid nodule

- thyroid cancer

- parathyroidectomy diagnostic procedure for thyroid cancer. Yet, false-negative results were reported in up to $10 \%$ of cases, especially in small, subcentimeter nodules. In line with our data and the literature, patients with PHPT should have both a detailed ultrasound addressing the thyroid and cytology of any thyroid nodule, including small subcentimeter lesions. Moreover, surgical flexibility, allowing intraoperative thyroid nodule sampling, should be considered even for "innocent" nodules.
\end{abstract}

\section{Introduction}

The coexistence of thyroid nodule and primary hyperparathyroidism (PHPT) presents a clinical diagnostic and management challenges. Previous investigations have reported a relatively high, but versatile, incidence of 12 to $52 \%$ of thyroid nodules in patients with $\mathrm{PHPT}^{1-3}$ and 5 to $26 \%$ among

received

August 11, 2014

accepted

November 4, 2014

published online

December 8, 2014 patients with PHPT with thyroid disease requiring surgery. ${ }^{3}$ Frequent thyroid nodules have also been detected by ultrasound (US) in patients with secondary hyperparathyroidism (SHPT). ${ }^{4}$ Other observations have indicated an increased risk for cancer in patients with PHPT, mainly of hematopoietic, breast, and urinary tract malignancies, but also endocrine neoplasms. ${ }^{5,6}$ With the exception of familial 
endocrinopathies, the association between hyperparathyroidism and thyroid cancer has neither frequently reported nor widely discussed. Therefore, the clinical significance of concomitant thyroid cancer and hyperparathyroidism remains unclear.

The objective of this study was to explore the presumed association between PHPT, thyroid nodularity, and thyroid cancer by conducting an exemplar case series study, specifically addressing small $(\leq 1 \mathrm{~cm})$, otherwise "innocent," nonsuspicious thyroid nodules (by preoperative US and cytology) copresenting in patients with PHPT scheduled for parathyroidectomy that intra- and postoperative surgical pathology revealed as papillary thyroid carcinoma (PTC). Additionally, relevant observations retrieved from the English literature addressing thyroid cancer and hyperparathyroidism (both PHPT and SHPT) were reviewed, processed, and presented.

\section{Methods}

This work has been approved by the local Institutional Review Board. An exemplar group of patients diagnosed with PHPT was studied. All had both a preoperative 99m Tc-MIBI (methoxyisobutyl isonitrile) scan and neck US suggesting a single parathyroid adenoma and were scheduled for an elective parathyroidectomy. In addition, all preoperative US studies demonstrated a small, benign-appearing thyroid nodule. US-guided fine needle aspiration (FNA) results from these thyroid nodules were also reported to be benign (II, according the Bethesda system for reporting thyroid cytopathology). ${ }^{7}$

All the patients were otherwise healthy, and none had any risk factors related to thyroid cancer according to the American Thyroid Association (ATA) 2009 guidelines (i.e., prior thyroid cancer, family history, or exposure to external irradiation). ${ }^{8}$

All patients underwent surgery in which a parathyroid adenoma was excised. By addressing these patients with PHPT as extra-suspicious for PTC, the thyroid lesion was sent for an intraoperative frozen section pathologic examination, which confirmed PTC. Thus, as planned and discussed before surgery, with consent given, total thyroidectomy was performed in addition to the parathyroidectomy.

\section{Results}

The preoperative workup and intraoperative courses of the four patients are summarized in -Table $\mathbf{1}$ and -Table $\mathbf{2}$, respectively. The postoperative recovery and follow-up were uneventful in all patients; postoperative parathyroid hormone and calcium blood levels returned to normal values. Surgical pathology of all the thyroid lesions was reported as PTC, classical variant, without evidence for an extracapsular spread (-Table 2). Patient 3 had an uneventful completion thyroidectomy 2 weeks after the first surgery, whereas patient 4 decided not to have completion thyroidectomy. Patients 1, 2, and 3 were later referred for ablative iodine 131 treatment.

The MEDLINE electronic database was searched to identify relevant studies. For this purpose, we used the following

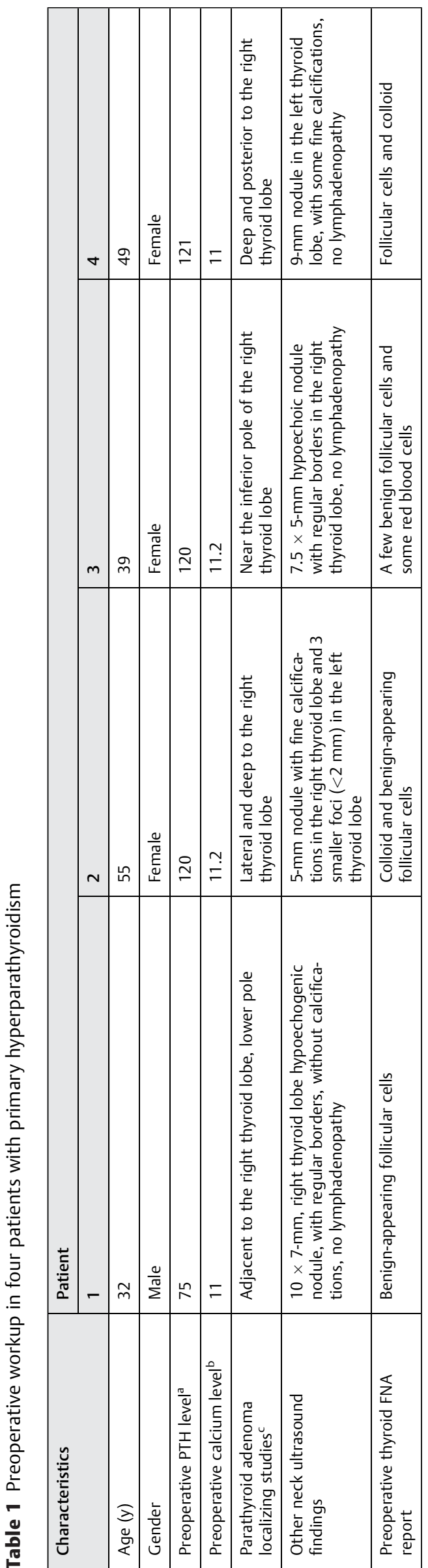


Table 2 Intraoperative course of four patients with PHPT

\begin{tabular}{|c|c|c|c|c|}
\hline & \multicolumn{4}{|l|}{ Patient } \\
\hline & 1 & 2 & 3 & 4 \\
\hline $\begin{array}{l}\text { Operative find- } \\
\text { ings in the thy- } \\
\text { roid field }\end{array}$ & $\begin{array}{l}\text { Firm nodule in the } \\
\text { right thyroid gland } \\
\text { upon palpation }\end{array}$ & $\begin{array}{l}\text { Firm nodule in the right thyroid } \\
\text { gland upon palpation, ill-looking } \\
\text { ipsilateral lymph nodes in levels } \\
\text { III, IV }\end{array}$ & $\begin{array}{l}\text { Firm nodule in the } \\
\text { right thyroid gland } \\
\text { upon palpation }\end{array}$ & $\begin{array}{l}\text { Firm nodule in the } \\
\text { right thyroid gland } \\
\text { upon palpation }\end{array}$ \\
\hline $\begin{array}{l}\text { Frozen section } \\
\text { report }\end{array}$ & PTC & PTC & Suspected PTC & Suspected PTC \\
\hline $\begin{array}{l}\text { Surgeon's } \\
\text { decision }\end{array}$ & $\begin{array}{l}\text { Total thyroidecto- } \\
\text { my }+ \text { level VI neck } \\
\text { dissection }\end{array}$ & $\begin{array}{l}\text { Total thyroidectomy + level VI } \\
\text { neck dissection + right levels III, } \\
\text { IV selective neck dissection }\end{array}$ & $\begin{array}{l}\text { Hold thyroidectomy; } \\
\text { wait for final patho- } \\
\text { logical result }\end{array}$ & $\begin{array}{l}\text { Right hemithyroidec } \\
\text { tomy; wait for final } \\
\text { pathologic result }\end{array}$ \\
\hline
\end{tabular}

Abbreviation: PTC, papillary thyroid carcinoma.

free-text terms: "hyperparathyroidism" with "thyroid cancer" or "risk factor" or "hypercalcemia," and limited to "human." In addition, relevant studies were also extensively searched for by hand. Time and language limitations were applied to the years 1900 to 2014 and English, respectively. Data regarding the occurrence of thyroid nodules among patients with PHPT were reported to match the general population. ${ }^{9,10}$ However, processing reported information regarding PTC among patients with PHPT who were operated for parathyroid adenoma suggested a 5\% incidence rate of coexistence of thyroid cancer and PHPT., ${ }^{1,9-15}$ The range varies between 3.3 and 15\% (- Table 3 ).

\section{Discussion}

This study questioned whether patients with PHPT have a higher risk for PTC in comparison with the general population. All the same, to date the ATA guidelines do not consider PHPT a risk factor for thyroid cancer. An increased awareness

Table 3 Papillary thyroid cancer among patients with PHPT undergoing parathyroidectomy

\begin{tabular}{|c|c|c|c|}
\hline Author & $\begin{array}{l}\text { No. of } \\
\text { PHPT } \\
\text { patients }\end{array}$ & $\begin{array}{l}\text { No. of } \\
\text { patients } \\
\text { with thyroid } \\
\text { cancer }\end{array}$ & $\%$ \\
\hline Attie and Vardhan ${ }^{2}$ & 948 & 31 & 3.3 \\
\hline Cinamon and Turcotte ${ }^{11}$ & 582 & 25 & 4.3 \\
\hline Strichartz and Giuliano ${ }^{12}$ & 308 & 11 & 3.5 \\
\hline Morita et al ${ }^{1}$ & 200 & 12 & 6 \\
\hline Rivo Vázquez et al ${ }^{13}$ & 124 & 6 & 4.8 \\
\hline Masatsugu et $\mathrm{al}^{9}$ & 109 & 19 & 17.4 \\
\hline Arciero et al ${ }^{14}$ & 94 & 6 & 6.4 \\
\hline Ogawa et al ${ }^{10}$ & 85 & 9 & 10 \\
\hline Gul et $a^{15}$ & 60 & 9 & 15 \\
\hline Total & 2,510 & 128 & 5 \\
\hline
\end{tabular}

Abbreviation: PHPT, primary hyperparathyroidism. and earlier diagnosis of PHPT has been partially attributed to the popular routine automated biochemical testing, in addition to targeting middle-aged women with blood calcium screening in an aging society. ${ }^{16}$ Furthermore, other reports suggested that patients with PHPT may have an elevated risk to encounter cancer including thyroid cancer. ${ }^{5,6}$ Concurrently, thyroid cancer incidence has been reported to increase worldwide. The reasons are not clear, yet an increased US detection rate of thyroid lesions is probably only a partial explanation. ${ }^{17-21}$ When based on physical examination alone, the incidence of thyroid nodularity was estimated to be $6.4 \%$ among female subjects and $1.5 \%$ in male subjects, and the incidence of thyroid nodules was 37 to $57 \%$ in autopsies series, with similar figures when detected by US. ${ }^{22}$

Contemporarily, FNA is the most valuable diagnostic procedure for PTC; however, false-negative results may be as high as $10 \%$, especially in small, subcentimeter nodules. ${ }^{23-25}$ This issue has been addressed by the revised ATA management guidelines for patients with thyroid nodules and differentiated thyroid cancer. These recommendations concluded that "routine FNA is not recommended for sub-centimeter nodules ... patients for whom consideration of FNA of a subcentimeter nodule may be warranted include those with a higher likelihood of malignancy (high risk history), i.e., family history of PTC, history of external beam radiation exposure as a child, exposure to ionizing radiation in childhood or adolescence, history of prior hemithyroidectomy with discovery of thyroid cancer, and 18FDG-PET [fluorine-18 fluorodeoxyglucose positron emission tomography]-positive thyroid nodules."8

Regarding "size," the current study presented four patients with PHPT, without any ATA-recognized risk factors for thyroid cancer, who presented with a small, unsuspicious thyroid nodule, which would not have been studied otherwise but nevertheless proved to harbor PTC in the postoperative pathologic examination. Roti et al reported that tumors $\leq 10 \mathrm{~mm}$ accounted for $39 \%$ of all thyroid cancers, and local lymph node invasion occurred in $0.8 \%$ of tumors $<5 \mathrm{~mm}$ and in 1.6 to $3.3 \%$ of patients with nodules 6 to $10 \mathrm{~mm}$ in size. ${ }^{26}$

Recent worldwide data reported the incidence of thyroid cancer to be $\sim 2$ to 12 per 100,000 per year new cases, and the 
estimated lifetime risk for developing thyroid among the general population was reported to be $1: 842$ for men and 1:324 for women (in the United Kingdom). ${ }^{17-21}$ Our original assessment of previously reported data suggested a high (5\%) rate of thyroid cancer among patients with PHPT undergoing parathyroidectomy (ranging 3.3 to $15 \%, 128$ thyroid carcinoma cases among 2,510 patients with PHPT; - Table 3). ${ }^{1,2,9-15}$ Although expressed in incomparable statistical measures, this rate suggests significance. Noteworthy are reports associating SHPT and thyroid cancer, thus contributing an additional argument that hyperparathyroidism may indeed predispose for thyroid cancer. ${ }^{27-29}$

Finally, a nontraditional operative approach (i.e., obtaining an intraoperative biopsy of a small thyroid nodule with a benign preoperative cytology) in a high-risk patient (with PHPT) has been shown to be rewarding. It is important to note that the intraoperative examinations of the thyroid nodules have been proven to be reliable, as described in the same context. $^{30}$

\section{Conclusion}

Larger population studies are required to determine if hyperparathyroidism is a significant risk factor for PTC. At this time, we suggest that patients with PHPT should be regarded as extra-suspicious for PTC. Therefore, a comprehensive preoperative thyroid workup, including FNA, should be performed in all patients with PHPT, even for small thyroid nodules $(\leq 1 \mathrm{~cm})$. Despite an otherwise innocent preoperative evaluation of a thyroid nodule in patients with PHPT, flexible surgical planning with optional intraoperative thyroid tissue sampling should be considered during surgery.

\section{References}

1 Morita SY, Somervell H, Umbricht CB, Dackiw AP, Zeiger MA. Evaluation for concomitant thyroid nodules and primary hyperparathyroidism in patients undergoing parathyroidectomy or thyroidectomy. Surgery 2008;144(6):862-866, discussion 866868

2 Attie JN, Vardhan R. Association of hyperparathyroidism with nonmedullary thyroid carcinoma: review of 31 cases. Head Neck 1993;15(1):20-23

3 Murray SE, Sippel RS, Chen H. Incidence of concomitant hyperparathyroidism in patients with thyroid disease requiring surgery. J Surg Res 2012;178(1):264-267

4 Sanai T, Okamura K, Inoue T, Abe T, Tsuruya K, Node K. Ultrasonographic detection of thyroid nodules in hemodialysis patients in Japan. Ther Apher Dial 2010;14(3):323-327

5 Nilsson IL, Zedenius J, Yin L, Ekbom A. The association between primary hyperparathyroidism and malignancy: nationwide cohort analysis on cancer incidence after parathyroidectomy. Endocr Relat Cancer 2007;14(1):135-140

6 Pickard AL, Gridley G, Mellemkjae L, et al. Hyperparathyroidism and subsequent cancer risk in Denmark. Cancer 2002;95(8): 1611-1617

7 Cibas ES, Ali SZ; NCI Thyroid FNA State of the Science Conference. The Bethesda System for Reporting Thyroid Cytopathology. Am J Clin Pathol 2009;132(5):658-665

8 Cooper DS, Doherty GM, Haugen BR, et al; American Thyroid Association (ATA) Guidelines Taskforce on Thyroid Nodules and
Differentiated Thyroid Cancer. Revised American Thyroid Association management guidelines for patients with thyroid nodules and differentiated thyroid cancer. Thyroid 2009;19(11):1167-1214

9 Masatsugu T, Yamashita H, Noguchi S, et al. Significant clinical differences in primary hyperparathyroidism between patients with and those without concomitant thyroid disease. Surg Today 2005;35(5):351-356

10 Ogawa T, Kammori M, Tsuji E, et al. Preoperative evaluation of thyroid pathology in patients with primary hyperparathyroidism. Thyroid 2007;17(1):59-62

11 Cinamon U, Turcotte RE. Primary hyperparathyroidism and malignancy: "studies by nature.". Bone 2006;39(2):420-423

12 Strichartz SD, Giuliano AE. The operative management of coexisting thyroid and parathyroid disease. Arch Surg 1990;125(10): 1327-1331

13 Rivo Vázquez A, Rivo Vázquez JE, Cáceres Alvarado $\mathrm{N}$, et al. [Hyperparathyroidism, goiter and well-differentiated thyroid carcinoma. A common association with diagnostic implications]. Cir Esp 2007;82(1):32-36

14 Arciero CA, Shiue ZS, Gates JD, et al. Preoperative thyroid ultrasound is indicated in patients undergoing parathyroidectomy for primary hyperparathyroidism. J Cancer 2012;3:1-6

15 Gul K, Ozdemir D, Korukluoglu B, et al. Preoperative and postoperative evaluation of thyroid disease in patients undergoing surgical treatment of primary hyperparathyroidism. Endocr Pract 2010;16(1):7-13

16 Adami S, Marcocci C, Gatti D. Epidemiology of primary hyperparathyroidism in Europe. J Bone Miner Res 2002;17(Suppl 2):N18-N23

17 Davies L, Welch HG. Increasing incidence of thyroid cancer in the United States, 1973-2002. JAMA 2006;295(18):2164-2167

18 Cancer Research UK. Thyroid cancer-UK incidence statistics. Trends over time. Available at: http://info.cancerresearchuk.org/ cancerstats/types/thyroid/incidence. Accessed August 27, 2014

19 National Cancer Institute of Canada. Canadian Cancer Statistics 2009. Time trends in incidence and mortality. Available at: www.cancer.ca

20 Pellegriti G, Frasca F, Regalbuto C, Squatrito S, Vigneri R. Worldwide increasing incidence of thyroid cancer: update on epidemiology and risk factors. J Cancer Epidemiol 2013;2013(13):965212

21 Aschebrook-Kilfoy B, Ward MH, Sabra MM, Devesa SS. Thyroid cancer incidence patterns in the United States by histologic type, 1992-2006. Thyroid 2011;21(2):125-134

22 Dean DS, Gharib H. Epidemiology of thyroid nodules. Best Pract Res Clin Endocrinol Metab 2008;22(6):901-911

23 Hambleton C, Kandil E. Appropriate and accurate diagnosis of thyroid nodules: a review of thyroid fine-needle aspiration. Int J Clin Exp Med 2013;6(6):413-422

24 Mehanna R, Murphy M, McCarthy J, et al. False negatives in thyroid cytology: impact of large nodule size and follicular variant of papillary carcinoma. Laryngoscope 2013;123(5):1305-1309

25 Shrestha M, Crothers BA, Burch HB. The impact of thyroid nodule size on the risk of malignancy and accuracy of fine-needle aspiration: a 10-year study from a single institution. Thyroid 2012; 22(12):1251-1256

26 Roti E, Rossi R, Trasforini G, et al. Clinical and histological characteristics of papillary thyroid microcarcinoma: results of a retrospective study in 243 patients. J Clin Endocrinol Metab 2006; 91(6):2171-2178

27 Maisonneuve P, Agodoa L, Gellert R, et al. Cancer in patients on dialysis for end-stage renal disease: an international collaborative study. Lancet 1999;354(9173):93-99

28 Cengiz K. Increased incidence of neoplasia in chronic renal failure (20-year experience). Int Urol Nephrol 2002;33(1):121-126

29 Miki $\mathrm{H}$, Oshimo $\mathrm{K}$, Inoue $\mathrm{H}$, et al. Thyroid carcinoma in patients with secondary hyperparathyroidism. J Surg Oncol 1992;49(3): 168-171

30 Yoon JH, Kwak JY, Kim EK, et al. How to approach thyroid nodules with indeterminate cytology. Ann Surg Oncol 2010;17(8): 2147-2155 